\title{
Trabalho Territorial em Hospitais Psiquiátricos - Construindo no Presente um Futuro sem Manicômios
}

\author{
Territorial Work in Psychiatric Hospitals - \\ Building a Future Without Hospices by Working in The Present \\ Trabajo Territorial en Hospitales Psiquiátricos - \\ Construyendo en el Presente un Porvenir sin Manicomios
}

Luís Felipe Ferro

Universidade

Federal do Paraná
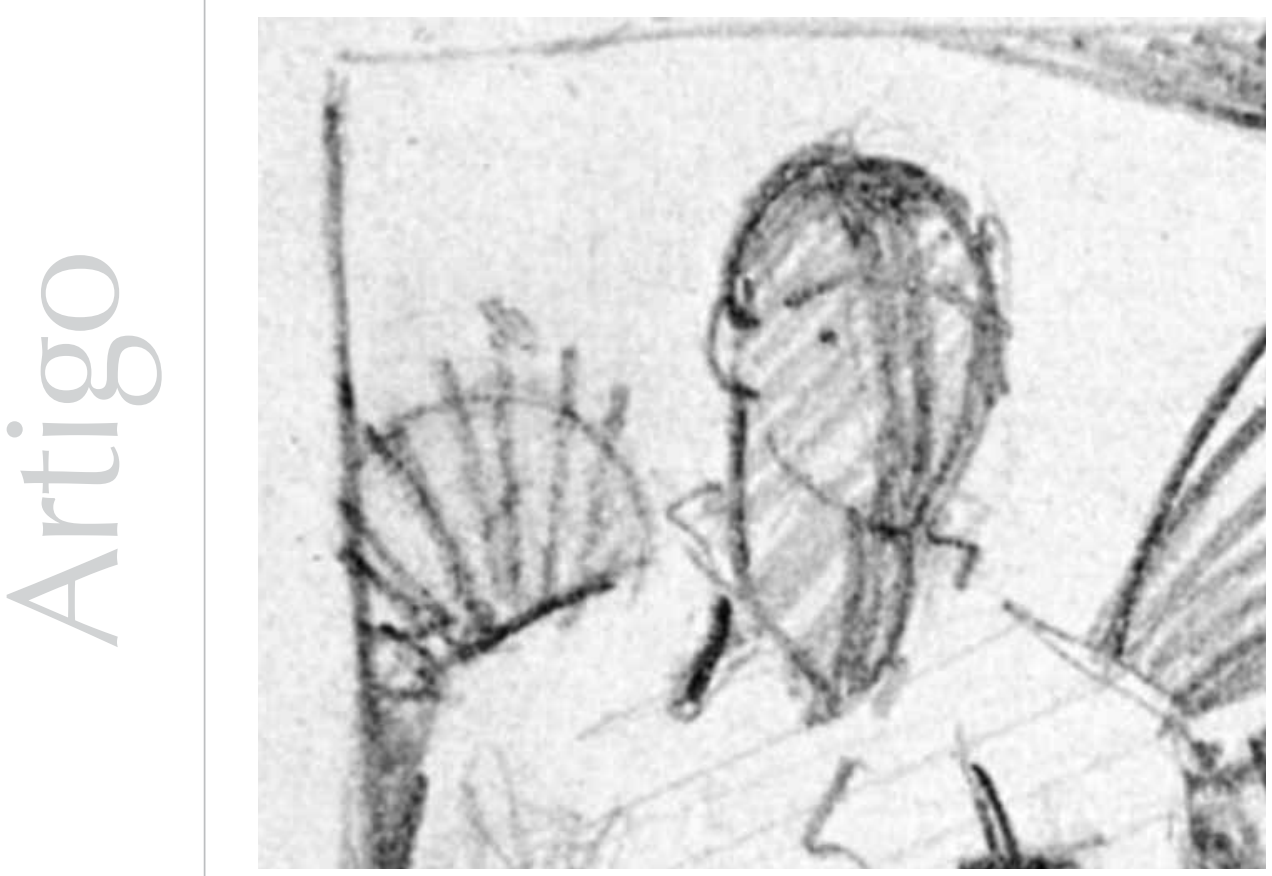
${ }^{1}$ Utilizo-me aqui dos conceitos foucaultianos de discurso e práticas discursivas para avaliar as transformações ocorridas na saúde mental, suas práticas e influências sociais. Para o autor, o discurso é composto por condições em constante mutação e localizadas espaço/ temporalmente, que sustentam a existência de determinadas práticas e enunciados. A prática discursiva "é um conjunto de regras anônimas históricas, sempre determinadas no tempo e no espaço, que definiram, em uma dada época e para uma determinada área social,

econômica, geográfica ou lingüística,

as condições de exercício da função enunciativa" (Foucault,

1995, p. 136). Para aprofundamento no tema, aconselho a leitura de Foucault

(1995).

Resumo: Tendo como pano de fundo o quadro da reforma psiquiátrica no Brasil, o presente artigo procura situar e diferenciar dois conceitos que considera mister para a transformação do modelo manicomial de assistência à saúde mental: desospitalização e desinstitucionalização. A partir do aprofundamento da discussão desses conceitos, ressalta a necessidade da desinstitucionalização da assistência à saúde mental, abrangendo tanto práticas terapêuticas quanto o desmonte dos hospitais psiquiátricos. Em proposta pragmática, procura reposicionar o papel e a atuação dos agentes da saúde vinculados ao hospital psiquiátrico, discutindo a possibilidade de desinstitucionalização de suas práticas terapêuticas pela proposição de um trabalho territorial. A estruturação e a aplicação prática desse trabalho visariam à montagem e ao fortalecimento de uma rede concisa de serviços e encaminhamentos que poderiam subsidiar a necessária transformação do paradigma da saúde mental e auxiliar a implantação dos serviços substitutivos, resgatando o débito da exclusão social contraída pela saúde mental junto à loucura e investindo na inclusão social e na cidadania da população atendida em situação asilar. O hospital psiquiátrico, ainda necessário para a garantia da assistência à saúde mental dado o atual quadro brasileiro de composição e estruturação dos serviços substitutivos, apresenta-se aqui como catalisador de sua própria reforma.

Palavras-chave: Reabilitação psicossocial. Hospitais psiquiátricos. Saúde mental. Reforma psiquiátrica.

Abstract: Assuming the Brazilian psychiatric reform as a background, this article aims to situate and differentiate two essential concepts in order to transpose the old model of mental health attention, centered in the psychiatric hospitals: dehospitalization and "desinstitutionalization". Exploring these concepts, the need of "desinstitutionalization" of the attention in mental health is underlined, emphasizing the necessary changes in the therapeutic practices as well as in hospitalization. In the pragmatic field, the article tries to re-set the role and the work of health professionals bound to psychiatric hospitals, arguing about the possibilities of desinstitutionalization of the therapeutic practices by proposing a community-based work. The organization and the practical application of this work focuses the creation or fortification of a solid net of community services that would subsidize the needful changes in the mental health paradigm and in the strengthening of substitute services. It might rescue the debit of social exclusion made by mental health, investing in social inclusion and in the citizenship of the individuals with mental disorders. The psychiatric hospitals, still needed for the mental health attention, considering the actual panorama of composition and constitution of the substitute services, becomes here the catalyzer of its own reform.

Keywords: Psychosocial rehabilitation. Psychiatric hospitals. Mental health. Psychiatric reform.

Resumen: Teniendo como telón el cuadro de la reforma psiquiátrica en Brasil, el presente artículo procura situar y diferenciar dos conceptos que considera menester para la transformación del modelo de manicomio de asistencia a la salud mental: deshospitalización y desinstitucionalización. Desde el ahondamiento de la discusión de estos conceptos, resalta la necesidad de la desinstitucionalización de la asistencia a la salud mental, abarcando tanto prácticas terapéuticas como el desmontado de los hospitales psiquiátricos. En propuesta pragmática, procura reposicionar el papel y la actuación de los agentes de la salud vinculados al hospital psiquiátrico, discutiendo la posibilidad de desinstitucionalización de sus prácticas terapéuticas por la proposición de un trabajo territorial. La estructuración y la aplicación práctica de ese trabajo pretenderían el montaje y el fortalecimiento de una red concisa de servicios y encaminamientos que podrían subvencionar la necesaria transformación del paradigma de la salud mental y auxiliar la implantación de los servicios sustitutivos, rescatando la deuda de la exclusión social contraída por la salud mental junto a la locura e invirtiendo en la inclusión social y en la ciudadanía de la población atendida en situación asilar. El hospital psiquiátrico, aún necesario para la garantía de la asistencia a la salud mental dado el actual cuadro brasileño de composición y estructuración de los servicios sustitutivos, se presenta aquí como catalizador de su propia reforma.

Palabras clave: Rehabilitación psicosocial. Hospitales psiquiátricos. Salud mental. Reforma psiquiátrica.

Ao leitor, poderia apresentar-se, praticamente em concomitância com o ato da leitura do título do presente trabalho, pronto estranhamento: trabalho territorial em hospitais psiquiátricos? Não estaria presente um tamanho antagonismo entre essas duas práticas discursivas ${ }^{1}$ da saúde mental que impossibilitaria qualquer relação de composição? Como o hospital psiquiátrico, local erigido na base da exclusão social, poderia relacionar-se com um território?

Pois bem, é nesse terreno, à primeira vista árido, que me percebi em prática profissional e no qual procurei desenvolver este trabalho.

Com minha formação acadêmica voltada para os ideais da reabilitação psicossocial 
2 Utilizo-me da definição "asilar" pautado em Carneiro e Rocha (2004). Esse conceito é considerado aqui socioinstitucional, abarcando tanto indivíduos em estado crônico da doença como aqueles que permanecem internados mesmo em ausência de sintomas. “O paciente asilar é aquele cujo sistema de trocas com a sociedade foi rompido, e cuja vida relacional restringe-se às relações que ainda mantém no interior da vida institucional. Em outras palavras, o paciente asilar é o morador de uma instituição de modo permanente" para o trabalho em saúde mental, tomando como tutores professores como Fernanda Nicácio, Elisabete Ferreira Mângia, Ianni Regia Scarcelli, Denise Dias Barros, Eliane Dias de Castro, Maria Isabel Garcez Ghirardi, figuras importantes no cenário atual da desinstitucionalização e da reabilitação psicossocial brasileiras, debruçando-me sobre a produção acadêmica de Franco Basaglia, Paulo Amarante, Benedetto Saraceno, Ana Pitta, Jairo Goldberg, Franco Rotelli, Foucault e outros, finalmente, em proximidade teórica e com a prática da experiência de desinstitucionalização da cidade italiana de Trieste, vi-me, por esses acasos do destino, trabalhando em um hospital psiquiátrico.

Choque conceitual, poderia pensar o leitor, e foi exatamente o que pensei e experienciei. Mas foi esse o desafio que me instigou naquele espaço: como considerar a transposição de um modelo pautado em relações de exclusão? Como desmontar toda uma tecnologia criada para normatizar, para docilizar corpos? Como investir em processos de subjetivação da população atendida em situação asilar², ampliar suas redes de suporte, como considerar sua inclusão social? Haveria alguma maneira possível de utilizar o espaço e algumas das tecnologias do hospital psiquiátrico para auxiliar e fortalecer o trabalho dos serviços substitutivos?

Para uma exploração mais pormenorizada dessas questões, é necessário, de antemão, situarmos adequadamente as críticas levantadas às propostas manicomiais e às propostas dos serviços substitutivos, explicitando, embora brevemente, o atual panorama da saúde mental no Brasil. Em seguida, exploraremos o terreno das políticas públicas que sustentam as transformações propostas na saúde mental, para, finalmente, propor aliança ao trabalho ainda existente do profissional da saúde dentro dos hospitais psiquiátricos e as premissas da reabilitação psicossocial.

\section{Hospital psiquiátrico e o modelo manicomial de atenção à saúde mental}

Atualmente, críticas incisivas no campo discursivo da saúde mental desferidas contra as propostas manicomiais acusam a compreensão social da loucura na qual estas foram sustentadas (Nicácio, 1995; Saraceno, 1999; Pitta, 1996; Rotelli, Leonardis, \& Mauri, 2001). Nessa compreensão, o sujeito atendido deveria ser retirado de seu meio social, internado em hospitais psiquiátricos, que, por sua vez, exerceriam sua função de cura do indivíduo e, após isso, poderiam devolvêlo novamente são e apto à convivência social. A palavra de ordem nessa concepção é a normatização do indivíduo atendido. “Esse é, portanto, um sistema de ação que intervém em relação a um problema dado (a doença) para perseguir uma solução racional, tendencialmente ótima (a cura)" (Rotelli et al., 2001, p. 26).

Essa compreensão, ainda presente nos dias atuais, retira do sujeito atendido o poder de decisão sobre sua vida e processo terapêutico, destitui-o de sua cidadania, impõe a ele uma existência em um plano de menosvalia de suas opiniões, desejos e potencialidades de vida. Tal plano de existência ainda priva o sujeito de seu próprio meio social, aprisionando a loucura em hospícios, com a intenção de causar uma pseudo-estabilidade para uma normalidade. Falha enfaticamente enquanto proposta de cura/normatização, conforme apontado por Rotelli et al. (2001) e amplamente por autores vinculados ao movimento de desinstitucionalização.

Para Rotelli, “...a cronicidade continua a ser o objeto por excelência, o problema e o sinal mais evidente da impotência da psiquiatria em alcançar a solução-cura (e os manicômios são a evidência concreta de tudo isso)" (p. 26). No plano do concreto, a proposta de saúde 
A exclusão,

no caso dos

loucos, produziu então um outro fenômeno, que a igualdade material apenas não supre: produziu... desfiliação. E esta se distingue da pobreza ou da privação de bens materiais por agregar à mesma a ruptura dos vínculos e a ausência de futuro, gerando invisibilidade social. (Silva, 2004, p. 22) mental no contexto manicomial ofereceria ao sujeito atendido, então, ser retirado prontamente de seu contexto de vida/família/ trabalho após um ou alguns episódios de sofrimento e surto, ser submetido a regras hospitalares frias e sem muita negociação em relação às flexibilidades da vida de cada interno. As vontades e os desejos dos indivíduos atendidos seriam descartados em prol de uma idéia pré-concebida do que seria saudável terapeuticamente para sua vida, e oferecer-se-ia em paralelo, e sem nenhum custo adicional, uma fragilização de sua rede de suporte, dado seu longo período de internação e de reclusão em um mundo que lhe é alheio.

Para esse último item, nos é necessária maior atenção para aprofundarmos as discussões que pretendemos neste trabalho.

Como efeito da causa "hospital psiquiátrico", pacientes com longo histórico de internação percebem na qualidade mais fenomênica de seus cotidianos o enfraquecimento de seus vínculos. Na grande maioria dos casos, a presença familiar da primeira internação se nulifica ou no mínimo se reduz exponencialmente em internações posteriores. O deslocamento consecutivo de sua vida, promovida pela internação psiquiátrica, desmonta amizades, vínculos trabalhistas, possibilidades de reorganização e recomposição de sua vida. O hospital cria um mundo para receber o indivíduo, à parte de suas necessidades reais, mundo que promove a exclusão, a fragilização de vínculos. Sustenta-se “...a hipótese de que o mal obscuro da Psiquiatria está em haver separado um objeto fictício, a 'doença', da 'existência global complexa e concreta' dos pacientes e do corpo social" (Rotelli et al., 2001, p. 26, grifos do autor).

Para familiares, tendo o hospital psiquiátrico como local de referência, a resposta à crise passa a se constituir sobre esse encaminhamento.
Crise após crise, internação após internação, surto após surto, o afrouxamento dos vínculos com a família acontece paulatinamente, e, sentindo-se desamparada no tratamento do indivíduo quando este se encontra no lar, agarra-se à solução que parece a mais simples e resolutiva: o abandono.

A exclusão, no caso dos loucos, produziu
então um outro fenômeno, que a igualdade
material apenas não supre: produziu...
desfiliação. E esta se distingue da pobreza ou
da privação de bens materiais por agregar à
mesma a ruptura dos vínculos e a ausência
de futuro, gerando invisibilidade social.
(Silva, 2004, p. 22)

O hospital psiquiátrico, a partir da premissa errônea e impalpável concretamente sobre a qual baseia sua atuação, a cura/normatização, sustenta práticas excludentes - sua resposta última, em vários casos, acaba se tornando o abandono à perpétua internação ou às internações tão recorrentes que nada de palpável pode ser estabelecido, organizado ou recuperado fora do espaço manicomial. É nesse quadro problemático que se inserem as críticas e no qual os serviços substitutivos propõem novas práticas discursivas.

\section{Reabilitação psicossocial e os serviços substitutivos ao modelo manicomial}

A partir das décadas de 60 e 70, em cenário internacional, começam a surgir movimentos, com destaque para a psiquiatria democrática italiana, que procuraram levantar debates contra as propostas manicomiais, buscando sua desconstrução e a proposição de novas possibilidades de atenção à saúde mental (Antunes, Barbosa, \& Pereira, 2002; Fassheber \& Vidal, 2007).

No Brasil, a partir dessa década, técnicos e usuários da saúde mental apontaram incisivamente e de forma sistemática a necessidade de reestruturação da assistência 
em saúde mental. O Movimento dos Trabalhadores em Saúde Mental (1987) une essas instâncias, usuários, familiares e técnicos, e estrutura-se como movimento social, reivindicando transformações no modelo manicomial de atenção à saúde mental (Carneiro \& Rocha, 2004).

Nesse contexto, a reabilitação psicossocial amplamente divulgada no âmbito da saúde mental e priorizada pelas políticas públicas atuais como proposta de assistência à saúde mental (Brasil, 2004) - toma corpo junto ao discurso da saúde, procurando propor alternativas para as problemáticas levantadas pelo modelo manicomial de atenção, assim como sua transposição.

Em vez da procura pela normatização da loucura, pela formatação do indivíduo atendido a um modelo preconcebido socialmente como ideal/normal, a reabilitação psicossocial tem suas práticas focadas em um objeto completamente diferente. Rotelli coloca:

\begin{abstract}
Mas, se o objeto, em vez de ser "a doença", torna-se "a existência-sofrimento dos pacientes" e a sua relação com o corpo social, então desinstitucionalização será o processo crítico-prático para a reorientação de todos os elementos constitutivos da instituição para esse objeto bastante diferente do anterior. (Rotelli et al., 2001, p. 30)
\end{abstract}

Mas de que objeto estamos falando aqui? $\mathrm{O}$ que é essa existência-sofrimento apontada por Rotelli? O que, na prática, obteríamos de diferença na atenção ao sujeito atendido e/ ou composição de serviços em saúde mental?

A resposta vem de solavanco às práticas pautadas no modelo manicomial. Critica com propriedade as atividades do profissional da saúde mental erigidas sobre o terreno manicomial.

Não caberia, nesse momento, o exílio do indivíduo atendido de sua própria vida; não se pensaria em normatizar o indivíduo em espaço institucional, para encaixá-lo em momento vindouro em uma sociedade que permanecesse estática.

Quanto ao enfoque na cura e da atuação na especificidade da doença e não na problemática ampla do contexto de vida do indivíduo atendido, Rotelli coloca:

Por isso esse primeiro passo da desinstitucionalização consiste no fato de que não se pretende enfrentar a etiologia da doença (ao contrário, renunciase efetivamente a qualquer intenção de explicação causal), mas, ao contrário, adotase a direção de uma intervenção prática que remonte à cadeia das determinações normativas, das definições científicas, das estruturas institucionais, através das quais a doença mental - isto é, o problema - assumiu aquelas formas de existência e expressão. Por isso, a reproposição da solução reorienta de maneira global, complexa e concreta a ação terapêutica como ação de transformação institucional. (Rotelli et al., 2001, p. 29)

O foco na existência-sofrimento coloca questionamentos para as práticas do modelo manicomial. $O$ atendimento passa a necessitar de um território, o território do indivíduo atendido, no qual as problemáticas próprias a esse sujeito possam ser vislumbradas e trabalhadas diretamente.

\footnotetext{
Não é a substituição da desabilitação pela habilitação, mas um conjunto de estratégias orientadas a aumentar as oportunidades de troca de recursos e de afetos: é somente no interior de tal dinâmica de trocas que se cria um efeito habilitador. (Saraceno, 1999, p. 112)
}

Procura-se preservar e fortalecer vínculos familiares e comunitários, resgatar o débito da exclusão que as práticas da saúde mental corroboraram, investindo na inclusão social dos indivíduos atendidos. Nesse outro conceito de saúde, procura-se, contra e acima da normatização, investir na qualidade de vida e nas demandas da população atendida. 
O problema não é a cura (a vida produtiva), mas a produção de vida, de sentido de sociabilidade, a utilização das formas (dos espaços coletivos) de convivência dispersa... A palavra de ordem é: do manicômio, lugar zero dos intercâmbios sociais, à multiplicação extrema das relações sociais... Se a relação com "a doença" tem sempre como referência um hospital, ambulatório etc, a relação de desinstitucionalização requer a relação com um território. (Rotelli, 2001, pp. 30, 36, 47)

E esses são os desafios que a saúde mental coloca para si mesma: como deslegitimar as práticas de exclusão social promovidas pelo manicômio em prol de uma suposta saúde? Como restituir, ao sujeito atendido, a condição de cidadão, que lhe vem sendo arrebatada por práticas da saúde? Como ampliar a circulação social, a rede de suporte, fortalecer vínculos familiares e sociais? Como promover a real inclusão social da população atendida?

Dois conceitos devem, ainda, antes de adentrarmos com maior propriedade em nosso objeto de pesquisa neste trabalho, ser abordados com certa cautela: a "desinstitucionalização" e a "desospitalização".

O movimento atualmente evidenciado de reforma psiquiátrica, presente categoricamente nas políticas públicas da saúde mental (Brasil, 2004), encontra em sua aplicação prática, no entanto, alguns obstáculos.

Qualquer mudança de ideais e práticas discursivas não inaugura de súbito todo um novo momento discursivo, em oposição completa ao que se conhecia (Foucault, 1995). Qualquer nova prática se instaura em um momento histórico, e não se vê livre de seus legados.

A prática da desinstitucionalização não prega a simples extinção dos hospitais psiquiátricos, mas baseia-se em uma mudança do paradigma no qual estes foram erigidos, que inclui diversas das tecnologias reabilitativas presentes atualmente.

O movimento da desinstitucionalização, se confundido com uma pobre desospitalização, resumir-se-ia a acabar com os espaços físicos dos hospitais psiquiátricos e perderia sua qualidade mais interessante, a transposição do modelo manicomial de atenção. Caso bastasse a desospitalização, "mini-hospitais psiquiátricos" territoriais seriam inaugurados e se chamariam Centros de Reabilitação Psicossocial (CAPS). Mudar-se-iam os nomes sem uma transformação no que a desinstitucionalização considera mister, a mudança na concepção de sujeito, de cura, de reabilitação, de inclusão social, de saúde e qualidade de vida - culminando em práticas totalmente diferentes das aplicadas nos hospitais psiquiátricos.

Prazeres e Miranda (2005) realizaram um estudo buscando compreender a relação entre um serviço substitutivo e um hospital psiquiátrico de uma cidade no interior de Minas Gerais, entrevistando, para tanto, alguns agentes envolvidos nesses dois serviços de saúde mental. Recorro à citação de uma entrevista, presente no corpo do texto, que creio ser emblemática. Disse o entrevistado: "Se o serviço substitutivo tiver funcionamento vinte e quatro horas, ele vira hospital psiquiátrico', [e disseram os autores] afirmamos que: se o hospital psiquiátrico resolver a questão da liberdade, ele vira um serviço substitutivo."

O processo de desinstitucionalização não pára na desospitalização. Se a desinstitucionalização for confundida com desospitalização e esta for mantida na aplicação prática em caráter exclusivo, replicar-se-iam todas as práticas segregatórias evidenciadas no hospital psiquiátrico - e a citação acima seria justa. Um mundo à parte seria novamente construído e diversas 
oficinas e atendimentos aconteceriam dentro do CAPS, circunscrevendo a loucura a esse espaço - a inclusão social e os ideais da reabilitação psicossocial não se sustentariam concretamente.

As questões principais da desinstitucionalização não se restringem à desospitalização; são maiores e englobam esta última. Se replicarmos o modo de funcionamento de um hospital psiquiátrico em um serviço substitutivo, não falaríamos de desinstitucionalização nem poderíamos falar em serviços substitutivos, só poderíamos discorrer a respeito de um mini-hospital psiquiátrico, localizado perto da residência dos pacientes, onde os pacientes seriam "soltos" para dormir em suas casas.

É essa a problemática que se apresenta à saúde mental, desligar-se de seus legados e compor novos conhecimentos e tecnologias para suas práticas.

Dessa forma, não basta desospitalizar. É preciso desinstitucionalizar, pois o que se encontra em jogo não é apenas um novo endereço, seja um asilo, um internato ou mesmo a família, em que a situação de tutela do sujeito seja mantida, mas a adoção de uma política de inclusão do paciente na vida social. (Carneiro \& Rocha, 2004)

Reiterando: para a reabilitação psicossocial e os serviços substitutivos, interessa enxergar e levantar desejos dos indivíduos atendidos e possibilitar a esses a participação social em outros papéis sociais que não os reservados à doença. Intenciona-se investir na ampliação de redes de trocas sociais do indivíduo, ao inseri-lo em um mundo de intersubjetividades. Não se trata mais de buscar a normalidade, mas de proporcionar a vivência da diferença, de criar mecanismos de funcionamento sociais que a abarquem em toda sua complexidade, de fortalecer uma rede de serviços que procure dar conta de toda a complexidade dos sujeitos atendidos. Caracteriza-se outro momento discursivo da saúde mental, o de uma revisão de seus paradigmas, o de outra concepção de saúde, que extrapole a intenção de normatização da loucura.

Antes de pousarmos em terreno firme e de apresentarmos a possibilidade (e a necessidade) de um trabalho concreto de desinstitucionalização "dentro" do espaço de um hospital psiquiátrico visando ao fortalecimento das práticas territoriais e dos serviços substitutivos, vejamos brevemente como se encontra a legislação brasileira em seu diálogo com a desinstitucionalização.

\section{Ode à desinstitucionalização}

Várias frentes, sustentadas pela legislação brasileira, vêm propondo a desospitalização que compõe o atual quadro da reforma psiquiátrica.

A Portaria GM no 2.077, de 31 de outubro de 2003, regulamenta o programa intitulado De Volta para Casa, criado pela Lei no 10.708 , de 31 de julho de 2003. Essa Lei instituiu “...o auxílio-reabilitação psicossocial para assistência, acompanhamento e integração social, fora de unidade hospitalar, de pacientes acometidos de transtornos mentais, internados em hospitais ou unidades psiquiátricas... em período igual ou superior a dois anos" (Brasil, 2003). Esse auxílio contempla indivíduos com “...alta hospitalar ou morando em residências terapêuticas, com suas famílias de origem ou famílias substitutas, ou formas alternativas de moradia e de convívio social" (Brasil, 2003).

Essa portaria ainda obriga a exclusão do leito do indivíduo que saiu da instituição hospitalar e a transferência dos recursos correspondentes para ações extra-hospitalares.

Outra portaria que nos interessa neste trabalho, a Portaria GM no 106, de 11 de fevereiro de 2000, legisla sobre a criação e a constituição dos intitulados Serviços 
Residenciais Terapêuticos, reservados para o atendimento de pessoas com transtornos mentais.

\section{Nessa Portaria,}

...entende-se como Serviços Residenciais Terapêuticos moradias ou casas inseridas, preferencialmente, na comunidade, destinadas a cuidar dos portadores de transtornos mentais, egressos de internações psiquiátricas de longa permanência, que não possuam suporte social e laços familiares, e que viabilizem sua inserção social. (Brasil, 2000)

Aqui também os leitos hospitalares reservados aos indivíduos transferidos para essa nova modalidade de atenção seriam excluídos da instituição ou descredenciados do SUS, realocando seus recursos.

Dois artigos dessa Portaria que nos interessam para a atual discussão são descritos na íntegra abaixo:

Art. 3 o Definir que aos Serviços Residenciais Terapêuticos em Saúde Mental cabe:

a) Garantir assistência aos portadores de transtornos mentais com grave dependência institucional que não tenham possibilidade de desfrutar de inteira autonomia social e não possuam vínculos familiares e de moradia;

b) Atuar como unidade de suporte destinada, prioritariamente, aos portadores de transtornos mentais submetidos a tratamento psiquiátrico em regime hospitalar prolongado;

c) Promover a reinserção dessa clientela na vida comunitária.

Art. 4을 Estabelecer que os Serviços Residenciais Terapêuticos em Saúde Mental deverão ter um projeto terapêutico baseado nos seguintes princípios e diretrizes:

a) Ser centrado nas necessidades dos usuários, visando à construção progressiva da sua autonomia nas atividades da vida cotidiana e à ampliação da inserção social; b) Ter como objetivo central contemplar os princípios da reabilitação psicossocial, oferecendo ao usuário um amplo projeto de reintegração social, por meio de programas de alfabetização, de reinserção no trabalho, de mobilização de recursos comunitários, de autonomia para as atividades domésticas e pessoais e de estímulo à formação de associações de usuários, familiares e voluntários;

c) Respeitar os direitos do usuário como cidadão e como sujeito em condição de desenvolver uma vida com qualidade e integrada ao ambiente comunitário. (Brasil, 2000)

Cito esses dois artigos para afirmar a importância das práticas de desinstitucionalização vinculadas ao processo de desospitalização e para ressaltar as premissas legais das residências terapêuticas.

Não esqueçamos ainda a Portaria no 52/ GM, de 20 de janeiro de 2004, que institui o Programa Anual de Reestruturação da Assistência Psiquiátrica Hospitalar no SUS, que reafirma a política de redução progressiva de leitos em hospitais psiquiátricos e desloca os recursos advindos dessa redução para serviços de suporte à desinstitucionalização.

Os três componentes principais do Programa são: 1) a redução progressiva de leitos (por módulos de 40 leitos), constituindo nova classificação para os hospitais a partir do número de leitos SUS, com recomposição das diárias; 2) estímulo às pactuações entre gestores e prestadores para que a redução se dê de forma planejada, prevendo a assinatura de um Termo de Compromisso e Ajustamento entre as partes na garantia de efetivação do programa e 3) redirecionamento dos recursos financeiros da internação para a atenção extra-hospitalar em saúde mental. Em suma, este programa estabelece um mecanismo 
organizador do processo de redução de leitos, com incentivo financeiro pela redução (priorizando os hospitais de menor porte) e pela melhor qualidade de assistência, aferida pelo PNASH - psiquiatria. (Brasil, 2004)

A revista Psicologia: Ciência e Profissão Diálogos, em seu 4o volume, de dezembro de 2006, disponibiliza alguns dados interessantes a respeito da diminuição gradual dos leitos hospitalares, em um artigo com o título "Em Nome da Inclusão".

O Brasil atinge o pico da política centrada na internação, totalizando 430 hospitais psiquiátricos em seu território nacional 73 públicos e 357 privados. De acordo com levantamento do Ministério da Saúde, divulgado em junho de 2006, o número de hospitais não passa de 228 .

E o número de leitos não pára de diminuir. De 72.514, em 1996, eles baixaram para 60.868 . em 2000, e, no ano passado (2005), caíram para 42.076. Por trás dessa mudança, esteve e continua presente o empenho de centenas de profissionais da área de saúde, além do esforço governamental... Atualmente (2006), além de 426 residências terapêuticas, existem 882 CAPS espalhados pelo território nacional, sendo que 29 deles funcionam 24 horas por dia. (Conselho Federal de Psicologia [CFP], 2006, p. 57)

Fassheber eVidal (2007, p. 196) ainda complementam:

No Brasil, atualmente, existem mais de 300 RTs (residências terapêuticas) distribuídas em 14 Estados, abrigando mais de 1.500 pessoas. Apesar de esse número parecer expressivo, pode-se dizer que esses serviços ainda estão em fase embrionária, representando apenas $11 \%$ do total previsto.

Em atual quadro da saúde mental, caracterizado pelo progressivo desmonte dos hospitais psiquiátricos, fica a pergunta: como poderiam os profissionais da saúde mental vinculados aos ainda existentes hospitais psiquiátricos aliar-se às premissas da reabilitação psicossocial em seu exercício profissional? Como poderiam esses agentes focar seus trabalhos e esforços técnicos para a inclusão social da população em situação asilar atendida? Haveria forma cabível de conjugar o trabalho "dentro" de um hospital psiquiátrico e o fortalecimento dos serviços substitutivos?

\section{O trabalho do profissional da saúde no hospital psiquiátrico: garantindo inclusão social, cidadania e fortalecendo serviços substitutivos}

Como vimos, a desinstitucionalização não se restringe somente a uma desospitalização, mas atravessa seus limites. Ela é a criação de um novo conjunto de tecnologias que procura responder às demandas do indivíduo atendido, procurando incluí-lo na vida social em base igualitária, garantindo sua participação no trabalho e em eventos socioculturais, de lazer, de formação e cidadania - sua inclusão social.

O fato é que, agradando ou não aos que defendem as premissas da reabilitação psicossocial, os hospitais psiquiátricos existem e ainda existirão por algum tempo, no mínimo até que os serviços substitutivos tomem corpo e consistência, até que uma rede concisa de serviços e encaminhamentos possa subsidiar a necessária transformação do paradigma da saúde. No entanto, dada a situação de existência dos hospitais psiquiátricos, como poderíamos considerar a inclusão social das pessoas que residem nesses locais? E aqui se instala a proposta de desinstitucionalização como mudança do modo de atuação dos profissionais da saúde. 
Em vez de reservarmos nossos esforços para a atuação dentro do hospital psiquiátrico, buscando resgatar a promessa falível da normatização do indivíduo atendido, através das técnicas da mais variada sorte, a desinstitucionalização nos levaria a pensar (e a agir) diferentemente. $\mathrm{E}$, se desmontássemos a idéia preconcebida do trabalho cabível dentro de um hospital psiquiátrico, da realização de grupos de atividades, oficinas, dos atendimentos grupais e individuais dos profissionais da terapia ocupacional, Psicologia, Medicina, mesmo que realizados da melhor forma cabível a partir do modelo manicomial, dentro do hospital psiquiátrico, o que nos sobraria? Qual seria nosso papel como agentes da saúde? Como transporíamos a função de aliados da norma para aliados dos indivíduos atendidos?

Pensando unicamente no atendimento dentro do hospital psiquiátrico, não vejo qualquer saída para essas questões. No entanto, e se transpuséssemos os muros dessa instituição, derrubando, nesse processo, nossos próprios muros imaginários há tanto cristalizados?

Implementar a desinstitucionalização requer instalar-se em um território, retomando as palavras de Rotelli et al. (2001, p. 47): “Se a relação com 'a doença' tem sempre como referência um hospital, ambulatório, etc, a relação de desinstitucionalização requer a relação com um território".

Caberia aos profissionais da saúde, nesse novo momento discursivo, abrir as portas do hospital psiquiátrico e aventurar-se pelo território, respirar novos ares junto à população atendida.

E se, ao invés de nos comportarmos como carcereiros, trancafiando a loucura e procurando docilizar corpos para uma internação mais "pacífica", empunhássemos a chave das portas (cuja posse infelizmente ainda detemos) e explorássemos, com pacientes asilares há tanto institucionalizados, a potencialidade de vida presente no mundo de fora?

Nesse novo papel, caberia a nós, profissionais da saúde, a inclusão social da população atendida, fortalecendo o diálogo de nossas práticas com o mundo de fora. No entanto, a primeira questão que se apresentaria seria: qual é esse mundo de fora?

Inicialmente, seria imprescindível, para adentrar nesse mundo com a população atendida, conhecê-lo adequadamente. Ao profissional da saúde, a missão inicial incumbida: levantar todas as possibilidades do território em que se instala o hospital psiquiátrico, levantar os diversos equipamentos sociais presentes nas proximidades do hospital psiquiátrico. $\mathrm{E}$, para responder às demandas dos usuários de nossos serviços nada nos é mais necessário do que a montagem concisa de uma rede de serviços e equipamentos sociais do local.

Exploraríamos, em um primeiro momento, a existência de espaços de cultura e lazer, de profissionalização, de cooperativas de trabalho, de igrejas e/ou centros religiosos, de estudo e formação, de ONGs, OSCIPs, associações e terceiro setor em geral. Área devidamente conhecida, as parcerias produtivas são sempre bem-vindas; em segundo momento, o trabalho sobre a criação e/ou fortalecimento de uma rede de serviços concisa, contactando as entidades e os equipamentos sociais em busca de elaboração de projetos conjuntos para atendimento da população alvo: internos psiquiátricos em situação asilar.

E aqui não pretendemos fixar nenhum projeto como imutável e imprescindível para toda e qualquer população/região/ hospital psiquiátrico, recorrendo a um erro cartesiano básico. Cada parceria e projeto 
${ }^{3}$ A Associação Beneficente da Saúde Mental, mais conhecida como Hospital Charcot. Trata-se de um hospital psiquiátrico com um dos quadros mais problemáticos da cidade de São Paulo.

${ }^{4}$ Igreja Evangélica Rio da Vida, situada em São Caetano do Sul, na rua Silvia, 1493. deverão procurar responder à diversidade das demandas de sua própria clientela, tendo como base a disponibilidade de serviços territoriais.

O que nos norteará, no entanto, serão premissas da reabilitação psicossocial já estabelecidas: a inclusão social, o respeito à cidadania, o trabalho sobre as demandas dos indivíduos atendidos, a procura pela criação de oportunidades de profissionalização, formação, participação cultural, social e política, o investimento em projetos de subjetivação do indivíduo atendido, o trabalho intersetorial e a criação de uma rede de serviços e encaminhamentos.

Através dos projetos obtidos, o profissional da saúde procurará resgatar a dívida da exclusão, que há tanto vem sendo contraída pela saúde mental em relação ao indivíduo atendido, garantindo a restituição de sua cidadania.

Um exemplo palpável para pousarmos de um plano ideário em terreno sólido ocorreu a partir de uma experiência profissional. Após levantar alguns equipamentos sociais das proximidades do hospital psiquiátrico onde trabalhei como terapeuta ocupacional ${ }^{3}$, algumas parcerias proveitosas puderam ser obtidas. Uma delas foi a composição de um projeto em conjunto com uma igreja evangélica ${ }^{4}$ local que apresentava forte preocupação e empenho com trabalhos sociais.

Nesse projeto, a igreja disponibilizou seu espaço e entrou em contato com vários fiéis para a composição e a ministração de aulas da mais variada sorte (artesanato, música, alfabetização, dança, etc) visando à formação/profissionalização/lazer dos indivíduos atendidos pelo hospital. A partir de projetos como esse, diversas frentes de trabalho poderiam se abrir: subprojetos de geração de trabalho e renda, de participação sociocultural, etc, sempre em diálogo com um mundo compartilhado e norteado pela inclusão social.

Em outro projeto realizado, a mesma igreja disponibilizou veículo próprio para transportar oito indivíduos em longa internação e fragilidade de vínculos familiares e conduzilos a seu culto principal, assim como para acolher esses indivíduos de maneira não estigmatizada. Em contra-partida, caberia aos profissionais da saúde em ambos os projetos: levantar demandas dos usuários para a participação nestes projetos, construindo esta participação em conjunto com o indivíduo atendido e respeitando suas vontades e desejos, investindo no resgate/fortalecimento de sua subjetividade/cidadania; preparar, embasado teoricamente na reabilitação psicossocial, os parceiros da igreja para o trabalho com a população da saúde mental, caso fosse necessário; acompanhar os indivíduos atendidos em seu percurso no projeto; trabalhar de maneira nãoassistencialista as relações interpessoais garantindo o acolhimento e participação social dos usuários; trabalhar a relação e vinculação do usuário ao local e parceiros; pensar em sub-projetos concomitantes e em estreito diálogo com os projetos iniciais, dado o exemplo do sub-projeto de geração de renda e trabalho, participação cultural, etc...

Dessa forma, mesmo trabalhando em um manicômio, os ideais e procedimentos próprios à desinstitucionalização podem ser postos em prática, corroendo por dentro essa máquina de "normatização" e "dessubjetivação" denominada "manicômio".

Outro projeto que exigiu nossa preocupação foi o trabalho com voluntários internos. Nesse trabalho, indivíduos da comunidade, contactados através do levantamento e da relação com as entidades e com as ferramentas sociais, eram acionados para ministrar aulas de diversas atividades, assim como para apresentar peças de teatro/música 
dentro da instituição. E aqui o perigo é iminente! Caso esse trabalho seja apropriado como fim em si, podemos até afirmar uma certa melhora na qualidade de vida das pessoas dentro dos hospitais psiquiátricos, mas jamais sua inclusão social! Caso seja afirmado e reafirmado incisivamente como um meio, através de práticas concomitantes que se utilizem do aprendizado das técnicas nas atividades oferecidas e reforcem a participação cultural e social do usuário, poderíamos falar em inclusão social, embora passíveis de críticas. Investiríamos na saída dessa produção, no levantamento de locais de escoamento, no trabalho em conjunto com os indivíduos com geração de renda, trabalho com participação sociocultural. A prática do voluntariado, entretanto, por si só, recairia na criação de um mundo paralelo à loucura. Apetece-me mais a idéia de transpor os limites institucionais/manicomiais em todo o percurso, pois o mesmo trabalho poderia ser realizado na comunidade, caso exista o oferecimento de aulas em espaços sociais ou este seja conseguido através de parcerias. $\mathrm{O}$ levantamento da possibilidade de inclusão dos usuários no mercado de trabalho, formal ou informal, em empresas capitalistas ou cooperativistas, ainda são oportunidades e parcerias que podem ser estabelecidas.

Creio que, neste momento, o trabalhador da saúde mental que se envolveu com o presente artigo pôde teórica e praticamente conceber os ideais da desinstitucionalização assim como vislumbrar concretamente a possibilidade da "destruição de muros" e do seu papel nesse processo. Recorro, no entanto, a mais duas experiências práticas para reforçar o conteúdo pragmático do artigo, ressaltando, contudo, a riqueza da variedade das experiências e dos projetos advindos das futuras parcerias desses profissionais quando em contato com um território.

Para quê restringirmos nossa atuação para dentro de quatro altas paredes cinza e frias?
Conhecendo o território, ainda poderíamos simplesmente andar até um SESC com alguns usuários que gostem de teatro e assistirmos uma agradável comédia. Quem já trabalhou ou trabalha em hospitais psiquiátricos conhece de perto a miserabilidade subjetiva do local e as cores e brilhos que provocariam nos olhos dos usuários um simples teatro. A saúde mental é pequena, se instala no mais usual da vida cotidiana. Quão grande seria nosso papel se investíssemos nessa pequena saúde mental!

Com o andar desse processo, com a abertura gradual das portas, a destruição progressiva dos muros mentais e físicos, quem sabe alguns usuários não poderiam sozinhos caminhar para seu destino, o teatro? Quão pequeno seria esse ato?

Poderíamos acionar, quando em contato com o território, voluntários externos, que poderiam, em primeiro momento, acompanhar os usuários para compor um cotidiano em que a saúde mental pudesse ser observada, em que a miséria subjetiva do manicômio pudesse ser transposta. Em um segundo momento, com um investimento maciço dessa nova forma de atuação na constituição das redes de suporte dos indivíduos atendidos, quem sabe o terapeuta ou o voluntário externo não dessem lugar a alguém que o usuário chamasse de amigo... bem pequeno, mas exatamente no lugar em que a vida se instala em potência...

Alguns profissionais poderiam considerar ser esse um trabalho excessivo - deslocar-se de nossas cômodas salas terapêuticas (nem tão cômodas em alguns hospitais psiquiátricos), tendo que transpor e/ou ampliar nosso usual setting terapêutico - mas esse trabalho, no entanto, se faz imprescindível caso queiramos falar de inclusão social, caso queiramos transformar a legitimidade da miserabilidade subjetiva própria ao modelo manicomial, se intencionamos o respeito à cidadania, o trabalho com a saúde, a qualidade de vida e o investimento na demanda dos indivíduos atendidos. 
Longe de excessivo, creio que as qualidades atribuíveis a esse trabalho poderiam ser: terapêutico, humanizador, necessário, subjetivante, desinstitucionalizante, transformador, inclusivo, instigante, desafiador. Longe de tomar tal trabalho como excessivo, creio ser esse somente um trabalho não usual ao que vem sendo praticado no manicômio, mas que pode facilmente tomar seu lugar - a ética para com o paciente, além de tudo, nos tomaria de ímpeto, e nos compeliria a realizá-lo.

Além disso, tais práticas podem ser sustentadas legalmente. A Portaria SNAS no 224, de 29 de janeiro de 1992, legislando a respeito das normas para o atendimento do hospital psiquiátrico, impõe a necessidade de preparar o indivíduo atendido para a alta, garantindo ainda a existência e o fortalecimento de um sistema de referência e contra-referência (Brasil, 1992).

Para além do manicômio, creio que esse trabalho ainda pode oferecer subsídios para os próprios serviços substitutivos repensarem algumas de suas práticas herdadas do modelo manicomial.

Um dos tópicos de discussão propostos pelo presente artigo ainda permanece descoberto: o fortalecimento dos serviços substitutivos a partir da prática do trabalho territorial em hospitais psiquiátricos. O que tem a contribuir o trabalho realizado em hospitais psiquiátricos para os serviços substitutivos, embora considerado territorialmente? Qual seria o diálogo entre essas duas práticas?

\section{Profissionais da saúde em hospitais psiquiátricos - preparando o futuro, intervindo no presente}

Dado irrevogável: os hospitais psiquiátricos conforme se apresentam atualmente não terão uma vida tão curta. A política nacional da saúde, embora se apresente incisivamente contra o modelo manicomial, projetando seu foco na desospitalização, na reforma psiquiátrica, na desinstitucionalização, ainda não apresenta estruturação suficiente para contar com o pronto fechamento dos hospitais psiquiátricos em âmbito nacional.

Residências terapêuticas, formas alternativas de moradia, serviços territoriais, trabalho sobre fortalecimento e manutenção de vínculos familiares vêm se estruturando na tentativa de descaracterizar a necessidade de internações prolongadas e de reconfigurar o modelo de atenção na saúde mental.

No entanto, um recado aos profissionais da saúde que trabalham em hospitais psiquiátricos: antes de serem tomados pelo medo da desapropriação do trabalho e de se apegarem firmemente às premissas exclusoras e desumanas do modelo manicomial, defendendo a continuação de sua existência em moldes usuais, tenhamos claro o novo momento da saúde e seus questionamentos. Procuremos transformar nossas tecnologias de acordo com tal momento, visando à humanização, à cidadania e à inclusão social na prestação de nossos serviços.

A contribuição dos agentes da saúde nos hospitais psiquiátricos para esse novo momento não pára por aqui. Dada a substituição do modelo manicomial por um modelo mais humano de atenção à saúde, algumas missões caberão a esses novos serviços e formas de atuação: montar uma rede concisa de encaminhamento entre os serviços presentes no território, de suporte e atenção aos indivíduos com transtornos mentais, incluir socialmente os indivíduos em longo período de internação, (re)apresentando-lhes o mundo e possibilidades de convívio social e garantindo sua participação no trabalho e em eventos socioculturais, de lazer e de formação, assim como no exercício de sua cidadania. 
Não cabe aqui a defesa da continuação da existência do espaço físico do manicômio, mesmo com a desinstitucionalização de suas práticas terapêuticas. A política da saúde mental está configurada para seu desmonte, e esse é um legítimo ganho social conquistado pelo movimento antimanicomial a partir de batalhas árduas.

Ao profissional da saúde, seria mais urgente resgatar a cidadania e investir na subjetividade e na inclusão social dos indivíduos atendidos nos hospitais psiquiátricos.

Através da prática dos profissionais da saúde mental nos hospitais psiquiátricos, transformada pelos ideais da reabilitação psicossocial, o fortalecimento dos serviços territoriais poderia ser evidenciado na montagem e na estruturação de uma rede de encaminhamentos e de serviços que tomaria corpo e serviria como subsídio para a composição dos serviços substitutivos.

Uma vez tal rede instalada e operante, os serviços substitutivos poderiam inserir-se nessa rede e gradualmente desinstalar o hospital psiquiátrico como referência da região para a saúde mental, aproveitando até mesmo a mão-de-obra dos agentes de saúde dos hospitais psiquiátricos, que teriam seu mesmo perfil e o ganho da familiaridade com a rede.

A inclusão social seria de pronto investida pelo hospital psiquiátrico, e, aos usuários de seus serviços, seria devolvida uma vida há tanto reduzida. Uma vinculação ao território seria composta junto aos indivíduos atendidos. Aos serviços substitutivos, como, por exemplo, as residências terapêuticas, em contrapartida, caberia respeitar a cidadania do indivíduo e o seu vínculo com o território, levando em consideração tais quesitos em sua pragmática. Propor-se-iam residências terapêuticas em determinadas regiões para dar conta de determinados cidadãos internados nessas regiões - não caberia retirar o indivíduo de seu território sem consultar sua vontade explícita. Que o indivíduo possa escolher que casa e que bairro habitar, que Ihe seja garantida o mínimo de cidadania em seu percurso vital.

Aos CAPS a serem instalados nas regiões dos hospitais psiquiátricos: serviços adiantados. A inclusão social já estaria sendo trabalhada. Transformações sociais que garantissem a presença da loucura em todos os âmbitos da sociedade, advindas do processo da inclusão, já estariam em movimento.

Aos serviços de saúde primária, pronta parceria poderia ser proposta, fortalecendo esses serviços para avaliar sua atuação junto à população da saúde mental, pensando em projetos de parceria para geração de renda com a comunidade de maneira ampla, investimento em participação social e criação de cooperativas de trabalho.

A desinstitucionalização das práticas terapêuticas não requer espaço físico diferente do manicômio. Os dois processos, desinstitucionalização de práticas terapêuticas e desmonte do hospital psiquiátrico, dificilmente acontecem simultaneamente. Pode haver uma desospitalização de uma região sem, no entanto, desinstitucionalizaremse as práticas terapêuticas - aqui se criariam os "mini-hospitais psiquiátricos". Importante, no entanto, é colocar em movimento, tanto no âmbito hospitalar quanto no âmbito substitutivo, a desinstitucionalização.

\section{Conclusão}

Aos que se aventurarem a aplicar os ideais da desinstitucionalização nos hospitais psiquiátricos ainda existentes, procurando investir em cidadania e subjetivação da população em situação asilar, uma observação: o problema é maior do que parece. 
Além dos altos muros e das barreiras psicossociais que colaboram para uma cronificação dos técnicos da saúde, diversas regras de funcionamento institucional deverão ser combatidas cotidianamente, e parcerias entre técnicos e administração hospitalar devem se afinar cada vez mais para proporcionar a concisão necessária aos projetos.

Tive a oportunidade de contar com uma equipe terapêutica em boa parte já formada pelos ideais da reabilitação psicossocial que apostou no trabalho proposto. Creio, infelizmente, que tal facilidade não será vivenciada por todos os agentes de saúde que optarem por esse caminho; no entanto, as parcerias fortalecem e dão cada vez mais corpo ao trabalho.

O trabalho que descrevemos neste artigo teve fim devido ao processo de fechamento do hospital psiquiátrico em que estava sendo desenvolvido - desfecho ideal por excelência. No entanto, tenho a inabalável certeza de que diversos conflitos permeariam a continuação do trabalho e teriam que ser cautelosamente tratados.

Refletir a respeito da desinstitucionalização requer mais do que pensar somente sobre a desospitalização. Caso esta tome a cena principal, nada será feito dentro dos hospitais psiquiátricos para colocar em andamento a desinstitucionalização. O hospital psiquiátrico não é condição impeditiva ao trabalho de desinstitucionalização, mas é, acima de tudo, afirmativo da necessidade interna dessa prática.

Em atuais configurações sociais da saúde mental, percebemos a necessidade de colocar em movimento o processo de desinstitucionalização, tanto dentro como fora do espaço físico do manicômio, visto que este ainda se encontra presente na atenção à saúde mental.
Do mesmo modo que um CAPS, uma residência terapêutica ou um serviço territorial, podem funcionar como um minimanicômio, e os hospitais psiquiátricos podem procurar transpor seus próprios limites desinstitucionalizando-se por dentro. Ainda haverá diversas e assertivas críticas referentes ao hospital psiquiátrico quanto à tutela dos indivíduos atendidos nesses espaços; no entanto, tomemos como certo o caráter transitório desses serviços e procuremos, mesmo dentro deles, fortalecer a reabilitação psicossocial e, acima de tudo, trabalhemos para resgatar a subjetividade do indivíduo atendido e sua relação com o mundo assim como sua condição de cidadania.

Em vez de atacarmos, através de críticas contraproducentes, tanto os hospitais psiquiátricos quanto os profissionais da saúde que prestam serviço nesses locais, tomemos a existência desses espaços como transitória e ainda necessária, dado o atual quadro de composição e estruturação dos serviços substitutivos. E se, em concomitância com a briga teórica, propuséssemos uma aliança prática? Construiríamos, assim, um futuro sem manicômios, agindo em um presente onde estes existem, através de profissionais com posturas, ideais e práticas desinstitucionalizadas. 


\section{Luís Felipe Ferro}

Terapeuta ocupacional formado pela Universidade de São Paulo, mestre pelo Departamento de Psicologia Social e do Trabalho pelo Instituto de Psicologia da Universidade de São Paulo, professor do curso de Terapia Ocupacional da Universidade Federal do Paraná, Curitiba, PR - Brasil.

\section{Endereço para envio de correspondência:}

Rua Padre Camargo, 280 - Alto da Glória, Curitiba, PR - Brasil - CEP: 80060-240 - A/C Departamento de Terapia Ocupacional - Setor de Ciências da saúde E-mail: luisfelipeferro@ufpr.br

Recebido 10/09/2008, Reformulado 07/01/20009, Aprovado 16/02/2009

Antunes, E. H., Barbosa, L. H. S., \& Pereira, L. M. F. (2002) História e arte no programa de saúde mental. In E. H. Antunes, L. H. S. Barbosa, \& L. M. F. Pereira (Orgs.), Psiquiatria, loucura e arte (pp. 25-32). São Paulo: EDUSP.

Brasil. Ministério da Saúde. (1990-2004). Legislação em saúde mental: 1990-2004 (5a ed. ampl.). Brasília, DF. Recuperado em 01 de julho de 2007, de http://portal.saude.gov.br/portal/ arquivos/pdf/Legislacao.pdf

Brasil. Secretaria Municipal de Saúde. (1992). Portaria SNAS $n^{\circ}$ 224, de 29 de janeiro de 1992. Recuperado em 05 de agosto de 2008, de http://www6.prefeitura.sp.gov.br/secretarias/ saude/legislacao/0161

Brasil. Ministério da Saúde. (2000). Portaria GM no 106, de 11 de fevereiro. Recuperado em 05 de agosto de 2008, de http:// portal.saude.gov.br/portal/saude/cidadao/visualizar_texto. cfm?idtxt $=23119$

Brasil. (2003). Portaria GM no 2.077, de 31 de outubro. Recuperado em 05 de agosto de 2008, de http://www. crefito5.com.br/web/sus/Portaria\%20n\%BA\%202.077\%20 de\%2031-10-2003.pdf

Brasil. (2004). Portaria GM no 52, de 20 de janeiro de 2004 Recuperado em 05 de agosto de 2008, de http://dtr2001. saude.gov.br/sas/PORTARIAS/Port2004/GM/GM-52.htm

Carneiro, N. G. O., \& Rocha, L. C. (2004). O processo de desospitalização de pacientes asilares de uma instituição psiquiátrica da cidade de Curitiba. Psicologia: Ciência e Profissão, 24(3), 66-75.
Conselho Federal de Psicologia. (2006, dezembro). Em nome da inclusão. Psicologia: Ciência e Profissão - Diálogos, (4), 56-58.

Fassheber, V. B., \& Vidal, C. E. L. (2007). Da tutela à autonomia: narrativas e construções do cotidiano em uma residência terapêutica. Psicologia: Ciência e Profissão, 27(2), 194-207.

Foucault, M. (1995). A arqueologia do saber (4a ed.). Rio de Janeiro: Forense Universitária.

Nicácio, M. F. S. (1995). O processo de transformação da saúde mental em Santos: desconstrução de saberes, instituições e cultura. Dissertação de Mestrado, Pontifícia Universidade Católica de São Paulo, São Paulo.

Pitta, A. (Org.). (1996). Reabilitação psicossocial no Brasil. São Paulo: Hucitec.

Prazeres, P. S., \& Miranda, P. S. C. (2005, junho). Serviço substitutivo e hospital psiquiátrico: convivência e luta. Psicologia: Ciência e Profissão, 25(2), 198-211. Recuperado em 05 de agosto de 2008, de http://pepsic. bvs-psi.org.br/scielo.php?script=sci_arttext\&pid=S141498932005000200004\&lng $=$ pt\&nrm $=$ iso

Rotelli, F., Leonardis, O., \& Mauri, D. (2001). Desinstitucionalização, uma outra via. In F. Nicácio (Org.), Desinstitucionalização. São Paulo: Hucitec.

Saraceno, B. (1999). Libertando identidades: da reabilitação psicossocial à cidadania possível. Rio de Janeiro: Instituto Franco Basaglia - Te Corá.

Silva, R. (2004, abril). Um parceiro da loucura. Psicologia: Ciência e Profissão - Diálogos, 1(1). 